\title{
Effects of Pancuronium Bromide on Cerebral Blood Flow Changes during Seizures in Newborn Pigs
}

MASSROOR POURCYROUS, CHARLES W. LEFFLER, HENRIETTA S. BADA, SHELDON B. KORONES, GREGORY L. STIDHAM, AND DAVID W. BUSIJA

Laboratory for Research in Neonatal Physiology, Departments of Pediatrics, Obstetrics and Gynecology, and

Physiology and Biophysics, The University of Tennessee, Memphis, Memphis, Tennessee 38163

\begin{abstract}
We investigated the effects of pancuronium bromide pretreatment on cerebral blood flow (CBF) during bicuculline-induced seizures in anesthetized piglets. Arterial blood pressure, gases, $\mathrm{pH}$, cerebral electrocortical activity, and CBF (radioactive microsphere) were monitored at baseline, $10 \mathrm{~min}$ after administration of pancuronium $(0.3 \mathrm{mg} / \mathrm{kg}$ i.v.; $n=9)$ or vehicle (normal saline; $n=$ 8 ), and again at 5,15 , and $60 \mathrm{~min}$ after bicuculline $(3 \mathrm{mg} /$ $\mathrm{kg}$ i.v.). No change in CBF from baseline was observed at $10 \mathrm{~min}$ after either saline or pancuronium treatment, before induction of seizures. In the saline group, CBF was $36 \pm 3$ $\mathrm{mL} \cdot \mathrm{min}^{-1} \cdot 100 \mathrm{~g}^{-1}$ before bicuculline and increased to 166 \pm 24 and $205 \pm 35 \mathrm{~mL} \cdot \mathrm{min}^{-1} \cdot 100 \mathrm{~g}^{-1}$ at 5 and $15 \mathrm{~min}$, respectively, after bicuculline, returning toward baseline by $60 \mathrm{~min}$. In the pancuronium group at $5 \mathrm{~min}$ after bicuculline, $C B F$ increased from $45 \pm 7$ to $169 \pm 26 \mathrm{~mL}$. $\mathrm{min}^{-1} \cdot 100 \mathrm{~g}^{-1}$, but fell to $88 \pm 17 \mathrm{~mL} \cdot \mathrm{min}^{-1} \cdot 100 \mathrm{~g}^{-1}$ at 15 $\mathrm{min}$ in contrast to saline-treated piglets. Also, at $15 \mathrm{~min}$ of seizures, differences between groups were observed in arterial blood pressure, gases, and $\mathrm{pH}$. Although these variables were in the normal range with pancuronium treatment, the saline-treated animals had increased arterial blood pressure $(81 \pm 6 \mathrm{~mm} \mathrm{Hg})$ and $\mathrm{PCO}_{2}(6 \pm 0.4 \mathrm{kPa})$ and decreased $\mathrm{PO}_{2}(7 \pm 0.5 \mathrm{kPa})$ and $\mathrm{pH}(6.91 \pm 0.06)$. Electrocortical activity was abnormal during seizures in both groups. At $60 \mathrm{~min}$, reversal to normal activity was observed in six of nine pancuronium-treated animals versus two of eight saline-treated animals. These data suggest that pancuronium limits cerebral hyperemia during prolonged seizures by attenuating increases in blood pressure as a result of elimination of skeletal muscle activity. This leads to minimal alteration of arterial $\mathrm{PCO}_{2}, \mathrm{PO}_{2}$, and $\mathrm{pH}$ during seizures. (Pediatr Res 31: 636-639, 1992)
\end{abstract}

Abbreviations

CBF, cerebral blood flow

MAA, muscle afferent activity

Severe intraventricular hemorrhage and hypoxic-ischemic encephalopathy are neurologic complications in neonates that are associated with subsequent presentation of seizures. Seizures are associated with major cardiovascular perturbations, including

Received June 20, 1991; accepted January 15, 1992.

Correspondence: Massroor Pourcyrous, M.D., Newborn Center, 853 Jefferson Ave., Room 201, Memphis, TN 38163.

Supported in part by grants-in-aid from the American Heart AssociationTennessee Affiliate, the National Institutes of Health, and Obstetrics and Gynecology Special Education Fund. dramatic increases in CBF (1). Factors contributing to augmented $\mathrm{CBF}$ are increased cerebral metabolic rate (2), metabolic and/or respiratory acidosis (3), and arterial hypertension (4-7). This rise in $\mathrm{CBF}$ is also exaggerated by neurogenic mechanisms (8). Babies prone to seizures often have respiratory problems and are given muscle relaxants to ease mechanical ventilation and oxygenation. However, inasmuch as pancuronium therapy has been reported to impair cerebrovascular autoregulation in neonatal animals (9), it is unclear whether such therapy would be beneficial.

The purpose of this study was to examine the effects of pancuronium on seizure-induced cerebral hyperemia in newborn pigs. We tested the hypothesis that pancuronium would limit perturbations of arterial blood gases, $\mathrm{pH}$, and blood pressure produced by skeletal muscle activity during prolonged seizures and consequently would limit increases in CBF during seizures.

\section{MATERIALS AND METHODS}

The animal protocol was reviewed and approved by the Animal Care and Use Committee of The University of Tennessee, Memphis. Seventeen newborn pigs $(1.2-2.2 \mathrm{~kg})$ of either sex, 2 to $5 \mathrm{~d}$ of age, were anesthetized with ketamine $(33 \mathrm{mg} / \mathrm{kg}$ intramuscularly) and acepromazine ( $3.3 \mathrm{mg} / \mathrm{kg}$ intramuscularly). The piglets were intubated and ventilated with air. A catheter was inserted into the femoral vein for injection of $\alpha$-chloralose $40 \mathrm{mg} / \mathrm{kg}$ initially, followed by $7 \mathrm{mg} / \mathrm{kg} / \mathrm{h}$. Two other catheters were inserted into the femoral arteries for withdrawal of reference blood samples and measurement of arterial blood $\mathrm{pH}$, gases (Instrumentation Laboratory, Inc., Lexington, MA), and blood pressure (Statham pressure gauge transducer and Gould recorder; Gould Inc., Cleveland, OH). A catheter was inserted directly into the left atrium for injection of microspheres. The chest was closed with clamps, and $1 \mathrm{~cm} \mathrm{H}_{2} \mathrm{O}$ positive end-expiratory pressure was maintained. Body temperature was maintained between 37 and $38^{\circ} \mathrm{C}$ using a water-circulating heating pad.

Electrocortical activity was monitored throughout the study using a filtered EEG (cerebral function monitor, model 870 ; Critikon, Tampa, FL) (10). Disk electrodes were placed on the scalp over the frontal and biparietal areas. The EEG signal was applied to a filter that cuts off signals below $2 \mathrm{~Hz}$ and above 15 $\mathrm{Hz}$ to eliminate electrical artifacts. The EEG tracings were interpreted blindly by one of the co-investigators (G.L.S.).

A 30-min period of stabilization followed the surgical procedures and catheter placement. Then, baseline CBF, arterial blood pressure, blood gases, and $\mathrm{pH}$ were determined. The piglets were randomized to receive either pancuronium bromide (Astra Pharmaceutical Products, Inc., Westborough, MA) at a dose of 0.3 $\mathrm{mg} / \mathrm{kg}$ i.v. or an equivalent volume of saline, and CBF was determined $10 \mathrm{~min}$ later. Then, seizures were induced by giving i.v. bicuculline (Sigma Chemical Co., St. Louis, MO) at $3 \mathrm{mg} /$ 
$\mathrm{kg}$; CBF, blood gases, and blood pressure were measured at 5 , 15 , and $60 \mathrm{~min}$ after injection. Cerebral metabolic rate for oxygen was not measured in this study because of the difficulty in maintaining the sagittal sinus catheter in place during seizure activity in the control piglets.

Radioactive microsphere determination of $C B F$. A known amount of radioactivity in $15-\mu \mathrm{m}$ microspheres $(300000$ 800000 microspheres) was injected into the left atrium, and the injection line was flushed with $1 \mathrm{~mL}$ saline. Withdrawal of reference blood samples $(1.03 \mathrm{~mL} / \mathrm{min}$ from the descending aorta) was begun $15 \mathrm{~s}$ before microsphere injection and continued for $1 \mathrm{~min}$ after the injection. Withdrawn blood was replaced with blood from a newborn pig donor. After each experiment, the piglet was killed, and the brain was removed and subdivided into major regions. The energies from the injected nuclides were separated by differential spectroscopy. Aliquots of the actual microsphere solutions injected were used for overlap calculations.

Blood flow to each brain region at each time of microsphere injection was calculated by using the formula $\mathrm{Q}=\mathrm{C} \times \mathrm{R} \times$ $\mathrm{CR}^{-1}$, where $\mathrm{Q}$ is the organ blood flow in $\mathrm{mL} \cdot \mathrm{min}^{-1} \cdot 100 \mathrm{~g}^{-1}, \mathrm{C}$ is counts $/ 100 \mathrm{~g}$ of tissue, $\mathrm{R}$ is rate of withdrawal of reference blood sample in $\mathrm{mL} \cdot \mathrm{min}^{-1}$, and $\mathrm{CR}$ is total counts in the reference withdrawal blood sample. A sufficient number of microspheres was injected to ensure that all brain regions contained at least 400 microspheres.

Statistical analysis. Values are reported as mean \pm SEM. For CBF changes, the analysis was carried out by using Friedman's analysis of variance, with the periods as the repeated measures. This allowed us to determine the significant changes that occurred over time within each of the two groups and between groups. When appropriate, Fisher's exact test was used for comparison between groups. The duration of seizures between groups was compared by Mann-Whitney U test.

\section{RESULTS}

Nine piglets received pancuronium bromide and eight received saline. Both groups had comparable baseline arterial blood pressure, blood gases, $\mathrm{pH}$, and regional and total brain blood flow values (Tables 1 and 2, Fig. 1). Ten min after administration of pancuronium or saline, there were still no differences in the above variables between the two groups.

No significant change occured in arterial $\mathrm{pH}, \mathrm{PCO}_{2}$, or $\mathrm{PO}_{2}$ in the pancuronium-treated group throughout the study. However, in the saline-treated group at 5 and $15 \mathrm{~min}$ of seizures, arterial
$\mathrm{PO}_{2}$ decreased and $\mathrm{PCO}_{2}$ increased; animals became severely acidotic throughout the $60 \mathrm{~min}$ of seizure activity.

At $5 \mathrm{~min}$ after seizure induction, mean arterial blood pressure increased significantly in both groups (Table 1). At 15 and 60 $\mathrm{min}$, however, blood pressure came down toward baseline in the pancuronium-treated group, but it remained significantly elevated in the saline-treated animals.

At 5 min of seizures, total brain blood flow (cerebral hemispheres, cerebellum, and brain stem) and regional CBF did increase in both groups to comparable levels, which were significantly greater than baseline (Table 2 , Fig. 1). However, in the medulla the rise in blood flow was significantly greater in the saline group compared with the pancuronium group. At $15 \mathrm{~min}$ of seizures, total CBF increased further in the saline-treated group when compared with the pancuronium-treated animals (Fig. 1). Also, when the blood flow in the saline group was compared with the baseline value, a significant rise was observed; blood flow was 8- to 9-fold greater than the baseline values in some regions such as caudate, pons, medulla, and diencephalon/mesencephalon (Table 2). However, in the pancuronium-treated group, $\mathrm{CBF}$ decreased from the 5-min measurements but values remained above baseline. By $60 \mathrm{~min}$ after seizure induction, total $\mathrm{CBF}$ returned toward baseline in both groups. Figure 2 shows blood pressure and $\mathrm{CBF}$ changes versus time in both groups; $\mathrm{CBF}$ and blood pressure were significantly increased at $5 \mathrm{~min}$.

A typical filtered EEG tracing (cerebral function monitor) is shown in Figure 3. In six of nine $(66.6 \%)$ pancuronium-treated animals, cerebral electrocortical activity reverted to normal within $60 \mathrm{~min}$ after seizure induction compared with only two piglets (two of eight, or $25 \%$ ) in the saline-treated group ( $p<$ $0.1)$. The duration of clinical seizure activity in saline-treated animals ranged from 35 to $>60 \mathrm{~min}$, longer than in the pancuronium group $(p<0.03)$.

\section{DISCUSSION}

The present study demonstrated that pancuronium administration attenuated increases in $\mathrm{CBF}$ in piglets during prolonged seizures. This effect may be due to a reduction in seizure-induced hypertension as a result of inhibition of motor activity. We speculate that this effect resulted from the normal oxygenation and metabolic status that were maintained and/or from elimination of skeletal muscle spindle afferent input to the brain. We also observed regional differences in CBF responses; brain stem structures had significantly higher increases in flow than the cerebrum during seizures. These findings were similar to those

Table 1. Arterial blood pressure, pH, blood gases, and total brain blood flow in pancuronium-and saline-treated piglets*

\begin{tabular}{|c|c|c|c|c|c|}
\hline & \multirow[b]{2}{*}{ Baseline } & \multirow{2}{*}{$\begin{array}{c}\text { Post } \\
\text { treatment }\end{array}$} & \multicolumn{3}{|c|}{ Seizures } \\
\hline & & & $5 \mathrm{~min}$ & $15 \mathrm{~min}$ & $60 \mathrm{~min}$ \\
\hline \multicolumn{6}{|c|}{$\mathrm{BP}(\mathrm{mm} \mathrm{Hg})$} \\
\hline $\mathrm{P}$ & $52 \pm 5$ & $55 \pm 5$ & $84 \pm 9 \dagger \ddagger$ & $56 \pm 6 \S \|$ & $55 \pm 5 \S$ \\
\hline $\mathrm{S}$ & $53 \pm 4$ & $49 \pm 4$ & $71 \pm 4+t$ & $81 \pm 6+t$ & $66 \pm 8 \neq$ \\
\hline \multicolumn{6}{|l|}{$\mathrm{pH}$} \\
\hline $\mathrm{P}$ & $7.41 \pm 0.03$ & $7.42 \pm 0.02$ & $7.36 \pm 0.03 \|$ & $7.37 \pm 0.04 \|$ & $7.35 \pm 0.06 \|$ \\
\hline $\mathrm{S}$ & $7.41 \pm 0.01$ & $7.41 \pm 0.02$ & $6.96 \pm 0.05 \dagger \ddagger$ & $6.91 \pm 0.06 \dagger \ddagger$ & $6.99 \pm 0.06 \dagger \ddagger$ \\
\hline \multicolumn{6}{|c|}{$\mathrm{PaCO}_{2}(\mathrm{kPa})$} \\
\hline $\mathrm{P}$ & $4 \pm 0.3$ & $4 \pm 0.1$ & $4 \pm 0.1 \|$ & $4 \pm 0.1 \|$ & $4 \pm 0.3$ \\
\hline$S$ & $4 \pm 0.1$ & $4 \pm 0.3$ & $7 \pm 0.5 \dagger \ddagger$ & $6 \pm 0.4 \dagger t$ & $5 \pm 1 \S$ \\
\hline \multicolumn{6}{|c|}{$\mathrm{PaO}_{2}(\mathrm{kPa})$} \\
\hline $\mathrm{P}$ & $11 \pm 0.8$ & $10 \pm 0.8$ & $10 \pm 0.8 \|$ & $10 \pm 0.8$ & $9 \pm 0.8$ \\
\hline S & $9 \pm 0.5$ & $10 \pm 0.3$ & $6 \pm 0.5+t$ & $7 \pm 0.5+\ddagger$ & $8 \pm 0.8$ \\
\hline
\end{tabular}

* Values are mean \pm SEM. Post treatment, 10 min after pancuronium or saline; BP. mean arterial blood pressure; P, pancuronium; S, saline; $\mathrm{PaCO}_{2}$, arterial $\mathrm{PCO}_{2}$; and $\mathrm{PaO}_{2}$, arterial $\mathrm{PO}_{2}$.

$+p<0.05$ compared with baseline.

$\ddagger p<0.05$ compared with post treatment.

$\S p<0.05$ compared with 5 min.

$\| p<0.05$ compared with saline. 
Table 2. CBF changes in pancuronium- and saline-treated piglets*

\begin{tabular}{|c|c|c|c|c|c|}
\hline & \multicolumn{5}{|c|}{ Flow $\left(\mathrm{mL} \cdot \mathrm{min}^{-1} \cdot 100 \mathrm{~g}^{-1}\right)$} \\
\hline & \multirow{2}{*}{\multicolumn{2}{|c|}{$\begin{array}{c}\text { Post } \\
\text { Baseline treatment }\end{array}$}} & \multicolumn{3}{|c|}{ Seizures } \\
\hline & & & $5 \mathrm{~min}$ & $15 \mathrm{~min}$ & $60 \mathrm{~min}$ \\
\hline \multicolumn{6}{|c|}{ Total cerebrum } \\
\hline $\mathrm{P}$ & $38 \pm 5$ & $41 \pm 7$ & $163 \pm 26 \dagger$ & $80 \pm 14 \S \|$ & $45 \pm 6 \S$ \\
\hline $\mathrm{S}$ & $32 \pm 3$ & $34 \pm 3$ & $143 \pm 19+\ddagger$ & $171 \pm 28 \dagger \neq$ & $61 \pm 14 \S \pi$ \\
\hline \multicolumn{6}{|c|}{ Caudate } \\
\hline $\mathrm{P}$ & $51 \pm 6$ & $54 \pm 13$ & $266 \pm 50+t$ & $135 \pm 30 \S \|$ & $74 \pm 17 \S$ \\
\hline $\mathrm{S}$ & $42 \pm 4$ & $39 \pm 5$ & $215 \pm 46+t$ & $317 \pm 75 \dagger \ddagger$ & $87 \pm 22 \S$ \\
\hline \multicolumn{6}{|c|}{$\begin{array}{l}\text { Diencephalon/ } \\
\text { mesenceph- } \\
\text { alon }\end{array}$} \\
\hline$P$ & $43 \pm 5$ & $49 \pm 9$ & $234 \pm 43+t$ & $137 \pm 41 \S \|$ & $61 \pm 12 \S$ \\
\hline $\mathrm{S}$ & $38 \pm 3$ & $36 \pm 3$ & $263 \pm 51+t$ & $340 \pm 63+\ddagger$ & $82 \pm 17 \S \pi$ \\
\hline \multicolumn{6}{|c|}{ 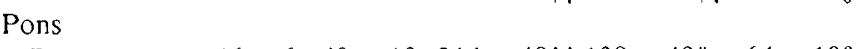 } \\
\hline $\mathrm{P}$ & $46 \pm 6$ & $49 \pm 10$ & $214 \pm 48 \dagger t$ & $139 \pm 40 \|$ & $64 \pm 10 \S$ \\
\hline S & $41 \pm 5$ & $41 \pm 4$ & $280 \pm 64 \uparrow t$ & $366 \pm 78 \dagger \ddagger$ & $87 \pm 16 \S$ \\
\hline \multicolumn{6}{|c|}{ Medulla } \\
\hline $\mathrm{P}$ & $50 \pm 6$ & $52 \pm 8$ & $112 \pm 24 \|$ & $84 \pm 15 \|$ & $62 \pm 10$ \\
\hline$S$ & $44 \pm 3$ & $42 \pm 2$ & $293 \pm 51 \dagger$ & $347 \pm 70 \dagger \ddagger$ & $87 \pm 17 \S$ \\
\hline \multicolumn{6}{|c|}{ Cerebellum } \\
\hline$P$ & $57 \pm 8$ & $63 \pm 10$ & $117 \pm 20 \dagger t$ & $87 \pm 10 \|$ & $68 \pm 8 \S$ \\
\hline S & $47 \pm 4$ & $50 \pm 4$ & $168 \pm 27 \dagger t$ & $244 \pm 43+\mp \S$ & $86 \pm 12 \S$ \\
\hline \multicolumn{6}{|c|}{ Gray } \\
\hline P & $43 \pm 7$ & $44 \pm 6$ & $199 \pm 41 \dagger \neq$ & $86 \pm 13 \S \|$ & $63 \pm 9 \S$ \\
\hline$S$ & $37 \pm 5$ & $40 \pm 5$ & $167 \pm 21 \dagger t$ & $145 \pm 36 t+$ & $86 \pm 21 \xi 9$ \\
\hline \multicolumn{6}{|c|}{ White } \\
\hline $\mathrm{P}$ & $35 \pm 6$ & $30 \pm 3$ & $168 \pm 26+t$ & $87 \pm 37 \S \|$ & $47 \pm 11 \S$ \\
\hline $\mathrm{S}$ & $28 \pm 4$ & $30 \pm 6$ & $136 \pm 29+\ddagger$ & $169 \pm 27 t \ddagger$ & $42 \pm 9 \S$ \\
\hline
\end{tabular}

* Values are mean \pm SEM. Post treatment, 10 min after pancuronium or saline; $P$, pancuronium; and $\mathrm{S}$, saline.

$\dagger p<0.05$ compared with baseline.

$\ddagger p<0.05$ compared to post treatment.

$\S p<0.05$ compared with 5 min.

$\| p<0.05$ compared with saline.

I $p<0.05$ compared with 15 min.

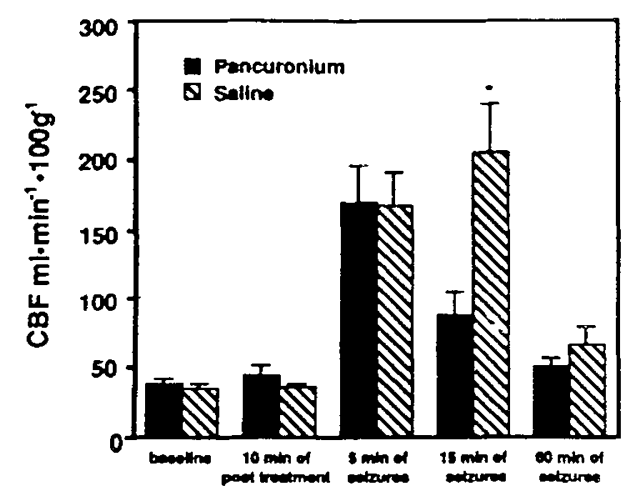

Fig. 1. Total brain blood flow in different periods in pancuronium and saline groups. Values are mean \pm SEM. ${ }^{*}, p<0.05$ compared with pancuronium.

observed in newborn lambs (6) and newborn monkeys (11) and could be attributed to differences in sympathetic innervation between the basilar and carotid circulation (11).

$\mathrm{CBF}$ has been reported to increase dramatically during seizures due to a number of factors, such as hypercapnia, hypoxemia, respiratory and metabolic acidosis (3), arterial hypertension (47 ), and neurogenic (8) and myogenic activities (12). Also, seizures increase cerebral metabolism, which leads to an increase in dilating mediators including $\mathrm{K}^{+}(13), \mathrm{H}^{+}(14)$, lactate $(15,16)$, adenosine $(15,16)$, and prostanoids $(17)$; these local mediators increase $\mathrm{CBF}$.

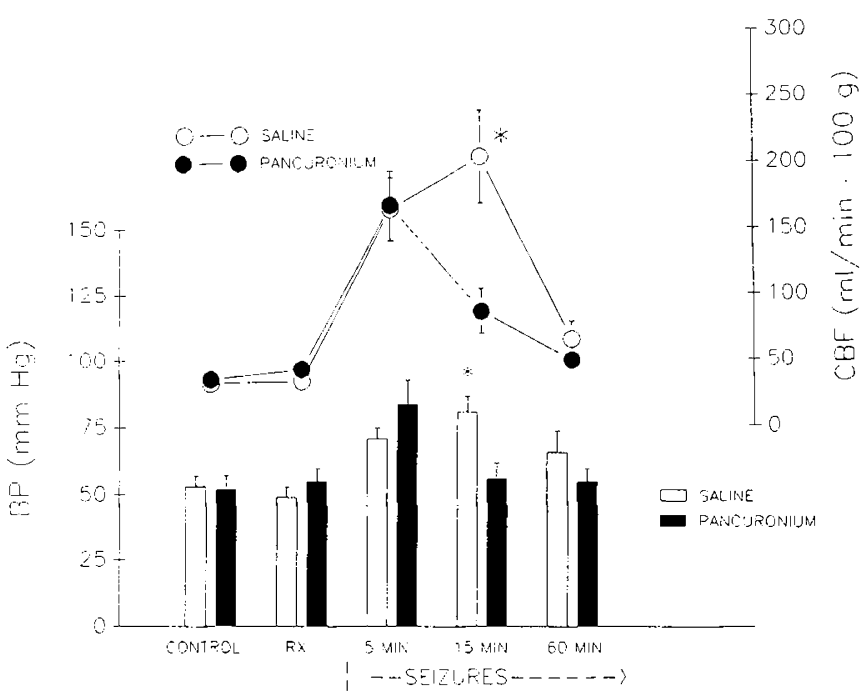

Fig. 2. Arterial blood pressure and total brain blood flow changes in saline- and pancuronium-treated piglets. ${ }^{*}, p<0.0005$ at $15 \mathrm{~min}$ of seizures.

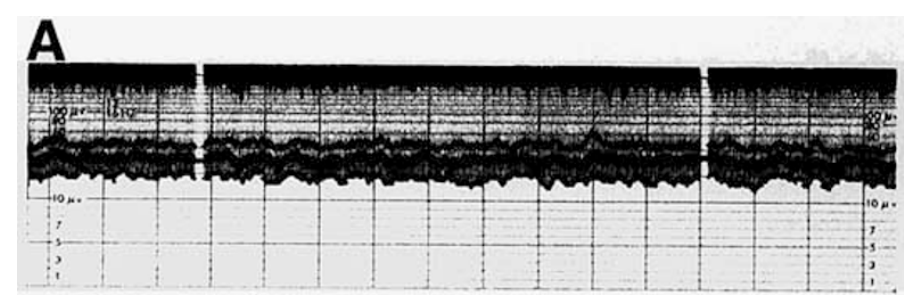

B

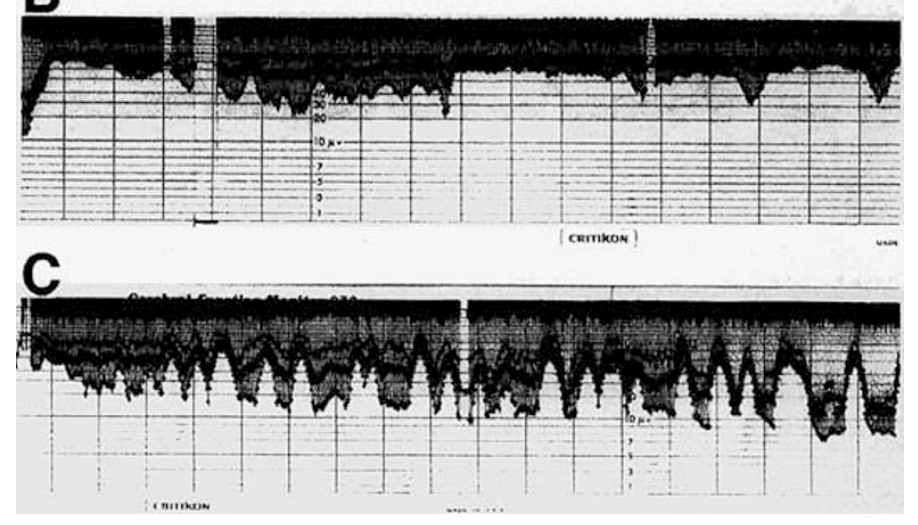

Fig. 3. Filtered EEG (cerebral function monitor) pattern seen in newborn pigs: $A$, normal pattern, no seizure activity; $B$, abnormal pattern, high-voltage seizure activity after bicuculline administration; $C$, abnormal pattern, seizure activity with spiky pattern. $X$ axis, time (30 $\mathrm{cm} / \mathrm{h}) . Y$ axis, peak electrical amplitudes $(0-100 \mu \mathrm{V})$.

Perturbations of arterial blood gases and pressure can accentuate increases in $\mathrm{CBF}$ during the seizures (8). However, changes in blood gases and $\mathrm{pH}$ in our animals cannot fully account for the cerebral hyperemia, inasmuch as these were constant in the pancuronium-treated animals, and CBF returned toward baseline in the saline-treated animals despite the presence of acidosis.

In both groups of animals, the initial increase in arterial blood pressure seen with seizures may possibly be of CNS origin related to the activation of cardiovascular centers in the brain (8). Plum et al. (8) reported that the increase in systemic blood pressure is responsible for $40-50 \%$ of seizure-associated cerebral hyperemia; this hyperemia can be abolished by blocking the sympathetic 
neural activity. However, the persistence of hypertension during seizures may be related to factors such as chemoreflex mediators $(18,19)$ and afferent neural activity arising from muscle spindles, which is referred to by other investigators as MAA (12). Active or passive skeletal muscle activity will result in increased MAA, which may modulate blood pressure (12). Increased arterial pressure might be expected to increase CBF proportionally as autoregulation is suspended transiently during seizure (8). In saline-treated animals, when the blood pressure continued to increase at $15 \mathrm{~min}$ of seizures, an additional increase in CBF was observed. In the pancuronium-treated animals at $15 \mathrm{~min}$ of seizures, blood pressure decreased toward baseline values with an associated decrease in CBF. Thus, in our animals, CBF changed similarly with blood pressure during seizures whether or not pancuronium was given.

There might be a concern over the use of pancuronium in babies with seizures. Monin et al. (9) have reported an impairment of $\mathrm{CBF}$ autoregulation in hypotensive piglets that received pancuronium. Our study was not intended to evaluate the role of pancuronium in $\mathrm{CBF}$ autoregulation. However, we did not observe any change in CBF after pancuronium administration before the onset of seizures. Furthermore, after seizure induction, the initial rise in $\mathrm{CBF}$ that accompanied the high blood pressure was the same in both groups. The subsequent changes in CBF also followed the changes in blood pressure in both groups.

The early normalization of EEG with pancuronium administration could be attributed to its inhibition of skeletal muscle activity, thereby eliminating the brain stimulatory effect of MAA (20). Furthermore, by eliminating motor seizure activity, less $\mathrm{O}_{2}$ would be consumed with lessened muscle $\mathrm{CO}_{2}$ and $\mathrm{H}^{+}$production. Therefore, more $\mathrm{O}_{2}$ would be available for brain consumption, and a normal systemic pH would be maintained as well. In adult animals, muscle paralysis during electroconvulsive shocks has been associated with minimal change in $\mathrm{pH}$ compared with a marked acidosis when saline was infused (3). The persistent metabolic acidosis in the saline-treated animals could have also prolonged the electrocortical abnormalities. This may be related to the effect of the acidosis on the seizure threshold. In cats, significantly more repetitive electrical seizures were tolerated if they were treated with sodium bicarbonate (3).

We speculate that using muscle relaxants would have the advantage of minimizing acid-base perturbations during prolonged seizures. By eliminating the skeletal muscle activity, oxygenation as well as metabolic state is maintained; this is associated with a shortened duration of abnormal electrocortical activity. Furthermore, pancuronium use would attenuate blood pressure increases and the cerebral hyperemia during seizures; such hemodynamic aberrations during seizures may contribute to alteration of the blood-brain barrier (7) and also intraventricular hemorrhage (21).
Acknowledgments. The authors thank Diane Loria and Ronnie Sabbah for excellent technical help. We also thank Wanda Wakefield for typing the manuscript and Kris Arheart for statistical analysis.

\section{REFERENCES}

1. Clozel M, Daval JL, Monin P, Dubruc C, Marelli PL, Vert P 1985 Regional cerebral blood flow during bicuculline-induced seizures in the newborn piglet: effect of phenobarbital. Dev Pharmacol Ther 8:189-199

2. Meldrum BS, Nilsson B 1976 Cerebral blood flow and metabolic rate early and late in prolonged epileptic seizures induced in rats by bicuculline. Brain 99:523-542

3. Wasterlain CG 1974 Mortality and morbidity from serial seizures. Epilepsia $15: 155-176$

4. Lou HC, Friis-Hansen B 1979 Arterial blood pressure elevations during motor activity and epileptic seizures in the newborn. Acta Pediatr Scand 68:803806

5. Perlman JM, Volpe JJ 1983 Seizures in the preterm infant: effects on cerebral blood flow velocity, intracranial pressure, and arterial blood pressure. $\mathrm{J}$ Pediatr 102:288-293

6. Kurth CD, Wagerle LC, Papadopoulos MD 1988 Regional regulation of the newborn cerebral circulation by sympathetic nerves during seizures. Am J Physiol 255:H563-H568

7. Mueller SM, Heistad DD, Marcus ML 1979 Effect of sympathetic nerves on cerebral vessels during seizures. Am J Physiol 6:H178-H184

8. Plum F, Posner JB, Troy BL 1968 Cerebral metabolic and circulatory responses to induced convulsions in animals. Arch Neurol 18:1-13

9. Monin P, Hascoet JM, Vert P 1989 Autoregulation of cerebral blood flow: effect of phenobarbital and pancuronium in the newborn piglet. Dev Pharmacol Ther 13:120-128

10. Stidham GL, Nugent SK, Rogers MC 1980 Monitoring cerebral electrical function in the ICU. Crit Care Med 8:519-523

11. Fujikawa DG, Dwyer B, Wasterlain CG 1986 Preferential blood flow to brainstem during generalized seizures in the newborn marmoset monkey. Brain Res 397:61-72

12. Lanier WL, Iaizzo PA, Milde JH 1989 Cerebral function and muscle afferent activity following intravenous succinylcholine in dogs anesthetized with halothane: the effects of pretreatment with a defasciculating dose of pancuronium. Anesthesiology 71:87-95

13. Kuschinsky W, Wahl M, Basse O, Thurau K 1972 Perivascular potassium and $\mathrm{pH}$ as determinants of local pial arterial diameters in cats. A microelectrode application study. Circ Res 31:240-247

14. Howse DC, Caronna JJ, Duffy TE, Plum F 1974 Cerebral energy metabolism, $\mathrm{pH}$, and blood flow during seizures in the cat. Am J Physiol 227:1444-1451

15. Winn HR, Welsh JC, Rubio R. Berne RM 1980 Changes in brain adenosine during bicuculline induced seizures in rats. Circ Res 47:568-577

16. Park TS, Van Wylen DGL, Rubis R, Berne RM 1987 Interstitial fluid adenosine and sagittal sinus blood flow during bicuculline seizures in newborn piglets. J Cereb Blood Flow Metab 7:633-639

17. Busija DW, Leffler CW 1989 Role of prostanoids in cerebrovascular responses during seizures in piglets. Am J Physiol 256:H120-H125

18. MacDougall JD, Tuxen D, Sale DG, Moroz JR, Sutton JR 1985 Arterial blood pressure responses to heavy resistance exercise. J Appl Physiol 58:785-790

19. Rutherford JD, Vatner SF 1978 Integrated carotid chemoreceptor and pulmonary inflation reflex control of peripheral vasoactivity in conscious dogs. Circ Res 43:200-208

20. Lanier WL, Milde JH, Michenfelder JD 1986 Cerebral stimulation following succinylcholine in dogs. Anesthesiology 64:551-559

21. Perlman JM, Goodman S. Kreusser K, Volpe JJ 1985 Reduction in intraventricular hemorrhage by elimination of fluctuating cerebral blood flow velocity in preterm infants with respiratory distress syndrome. $N$ Engl J Med $312: 1353-1357$ 